\title{
Church, Crown and City: changing fortunes in controlling health care
}

\author{
Nick Black
}

J R Soc Med 2007; 100:85-89

This is the first of four articles, each of which provide the background to one of the walks in a new book, Walking London's Medical History, which aims to tell the story of how health services developed, to help preserve our legacy of buildings and to inform current debates about health care. Walking London's Medical History is available from the RSM Press website: http: / / www.rsmpress.co.uk/bkblack2.htm

Usually, to enhance our understanding we sit and read books or, nowadays, surf the internet. But it's more fun to go out and literally visit the past, see the buildings where events unfolded and transport yourself back in time. And for the history of health care in England, there is nowhere better to do this than in London. For it was in London that most of the key developments took place: it was here that the key battles were fought over health care policies, where conflicts were resolved and where many innovations occurred. Although some of the important buildings in the history of health care have been destroyed, many remain.

A walk through Covent Garden illustrates how the fortunes of the Church, the Crown and the City have changed over time, how they have competed with one another despite their mutual dependency, and the impact this has had on the development and provision of health care. The highlights of the walk are shown in Box 1 .

\section{THE CHURCH TRIUMPHANT}

Before 1200 the Church was the principal provider of institutional care, reflecting both its Christian mission and its immense power. There were over 100 churches in the city and much of the land outside the city walls was owned by religious orders. Between 1100 and 1300, the bishops built themselves 45 ecclesiastical palaces, many along the river Thames, south of the Strand, to provide themselves with a London base for their political dealings. On a more altruistic note, the Church established hospitals outside the city walls. Apart from those with a general remit, such as $\mathrm{St}$ Bartholomew's and St Thomas's, ten were specifically for leprosy sufferers, including St Giles Hospital (Box 2).

Professor of Health Services Research, London School of Hygiene \& Tropical Medicine, Keppel Street, London WC1E 7HT, UK

E-mail: Nick.Black@Ishtm.ac.uk

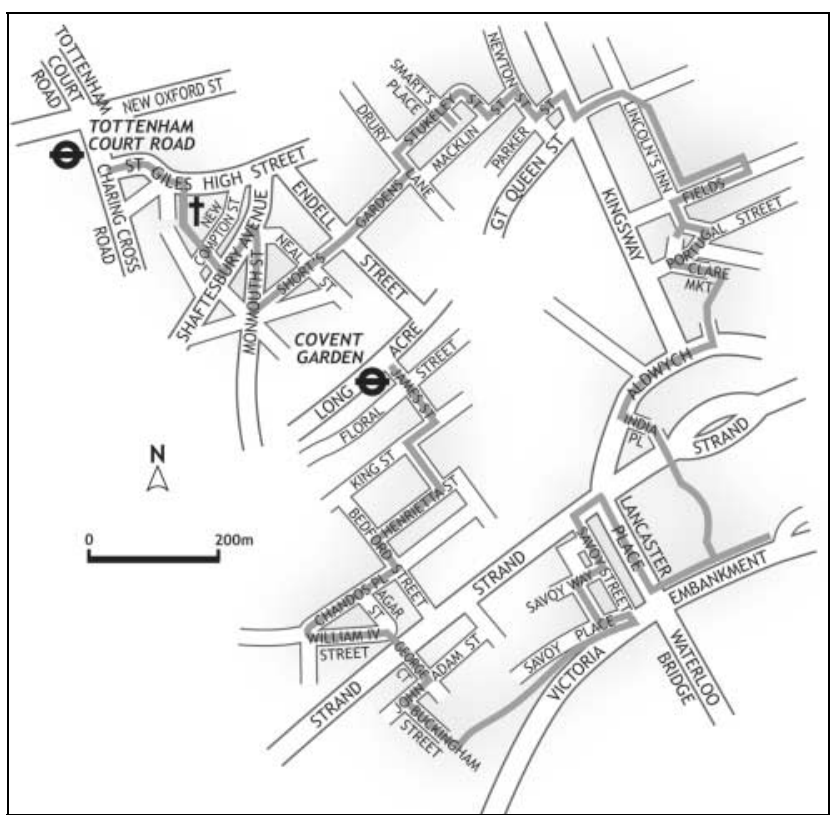

Figure 1 A map of the route.

\section{Box 1 Highlights of the walk}

- Sites of two medieval hospitals (St Giles, St Mary Rounceval)

- Poor Law infirmary (Strand Union Workhouse Infirmary)

- Royal College of Surgeons

- Site of the largest hospital in Britain before 1680 (The Savoy)

- British Medical Association's former home that scandalized Edwardian London

- First maternity hospital in England (British Lying-In Hospital)

- Three 19th century specialist hospitals (Royal Westminster Ophthalmic, St Peter's for Stone, Hopital et Dispensaire Francais)

- Two of London's great teaching hospitals and medical schools (King's College, Charing Cross)

However, a key source of the Church's power was to prove its undoing. The concept of purgatory instilled fear in the affluent for it promised suffering for the rich and unrepentant, who in the afterlife would be judged by the poor and the meek. This fear was exploited by the Church, which offered salvation (through the sale of indulgences) to those who bestowed gifts during their lives and endowments on their death. The rich would endow chantries, in essence paying the living to pray for their souls after death. And what better to endow than hospitals, with their poor, infirm inmates with nothing better to occupy their time than praying? 


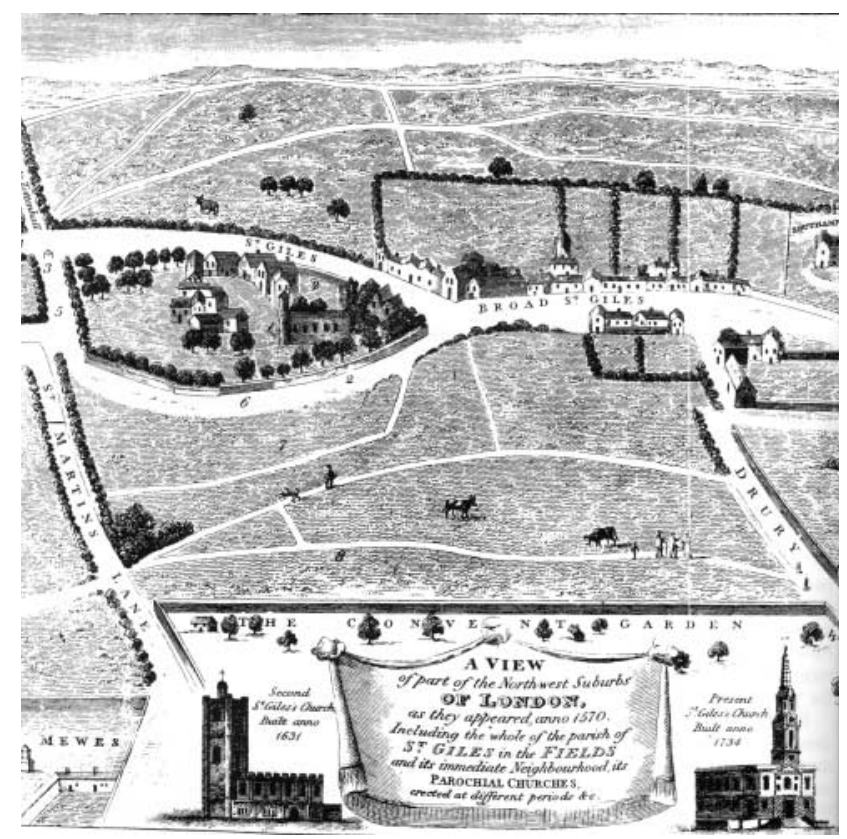

Figure 2 St Giles Hospital showing the chapel and, on the far right of its extensive grounds, spittle houses for leprosy patients

\section{Box 2 St Giles Hospital for Lepers}

Unusually for the time, it was founded by the Crown, specifically by Matilda, wife of Henry I. The hospital grounds covered a triangle bordered by modern-day St Giles High Street, Charing Cross Road and Shaftesbury Avenue (Figure 2). Apart from a chapel (on the site of the present church) there were four spittle (hospital) houses to accommodate 40 patients, and the Master's house. The rest of the extensive site was farmed by the patients and staff. While nominally for those suffering from leprosy, many of those consigned here are likely to have had other skin conditions, indistinguishable at the time from leprosy.

Governance of the hospital was contested over several centuries between the Church, Crown and City. One example of the hostility between Crown and Church occurred around 1300. To put St Giles Hospital out of the reach of the Bishop of London, Edward I granted ownership to a religious order from Navarre (northern Spain). This so displeased the Archbishop of Canterbury that he forcibly entered the hospital. Similarly, an example of conflict between City and Church occurred in 1334 when the City, which had the exclusive right to consign lepers to the hospital, discovered that the religious order running the hospital was turning it into a monastery by ousting lepers and installing monks. And yet another example of conflict between Church and Crown occurred in 1391: following the Bishop of London's forced entry with an armed band, the Crown gave the hospital to the Abbott of St Mary Graces (Tower Hill).

Despite the gradual disappearance of leprosy, the hospital survived until the Reformation when, in 1539, everything but the chapel (which survived until 1624) was demolished.

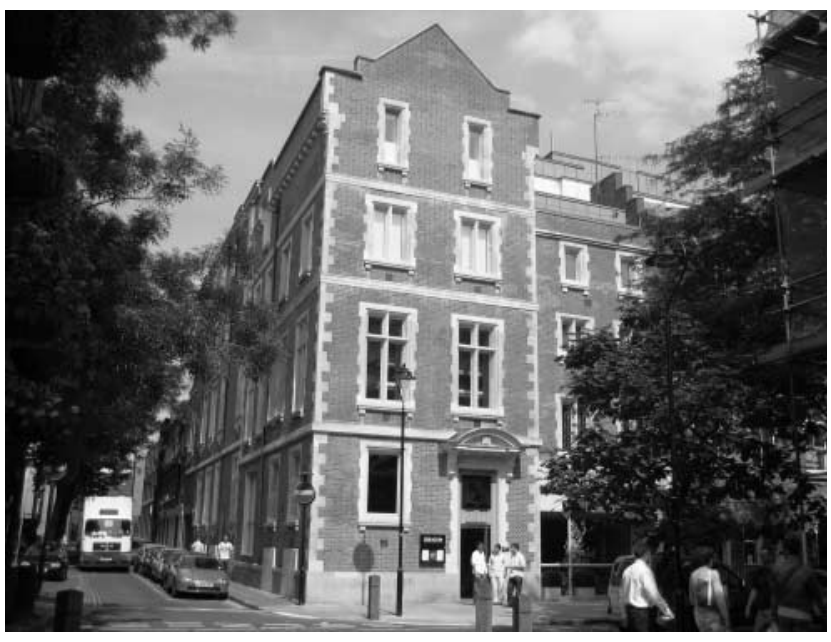

Figure 3 Built as the British Lying-In Hospital in 1845, this building was subsequently home to St Paul's Hospital from 1921-1992

\section{Box 3 British Lying-In Hospital for Married Women}

One of the hazards that faced impoverished women was childbirth. Until the middle of the 18th century, the only assistance available was from self-trained midwives, who were themselves mostly uneducated women from poorer classes. Influenced by the development of forceps in France, doctors in London started showing an interest in childbirth in the 1730s. The first hospital with so-called 'man-midwives' (including the leading surgeon, William Hunter) was the Middlesex Hospital in 1745. Following a falling-out with their medical colleagues, who objected to what they saw as the overuse of beds for childbirth, the 'man-midwives' decided to set up their own lying-in hospital.

The British Lying-In Hospital for Married Women was established in 1749 in Brownlow (now Betterton) Street. The building has long since been demolished. Women were admitted to the 20 beds in the last month of pregnancy and remained in hospital for three weeks after delivery. Demand was such that patients were selected randomly by drawing coloured balls from a bag. On leaving they had to 'give thanks' and were quizzed by the governors as to their views of the quality of their care-a level of concern rarely achieved today. Despite such an exemplary approach, the hospital attracted criticism in 1751 when a 'Petition of the Unborn Babe' was sent to the Royal College of Physicians claiming 'experiments' were leading to the deaths of mothers and babies. This proved to be no more than a minor irritation to the governors and in the 1840s, when the creation of Endell Street provided the opportunity to expand, a Jacobean style red-brick building was built (now housing a private club, The Hospital) (Figure 3). This served as a lying-in hospital until 1913, when it moved to Woolwich to merge with the Home for Mothers and Babies.

The Church had to coexist with the Crown. The power of the latter fluctuated depending on the skill and ability of the monarch, the extent to which the monarch was distracted by overseas exploits, and the level of control over 


\begin{abstract}
Having failed in the 1830 s to persuade the recently established Charing Cross Hospital to provide clinical experience for its medical students, King's College (on the Strand) was forced to make other arrangements. King's College Hospital opened in 1840 in a renovated 18th century workhouse with 120 beds, for which Mrs Ward, the matron, had six nurses and seven helpers. Their lack of training and skills was increasingly of concern to the governors, though it was no worse than other voluntary general hospitals in London. In an historic move in 1856, the nursing service was taken over by the Anglican nursing sisterhood of St John's House, the first major 'contracting out' of a hospital activity in the UK. Of even greater importance, it heralded the transformation of hospitals from places of danger to the citadels of healing they were to become in the 20th century.
\end{abstract}

The former workhouse building was replaced in 1860 by a grand 200-bed hospital built on sanitarian principles (Figure 4). It included an operating theatre, which accommodated 300 students, and a chapel accommodating 200, reflecting the hospital's religious commitment. Foreman, the tall, burly and domineering hall porter, extracted a shilling from each student to pay for planting the flower bed in front of the hospital.

Although the new nursing regime led to major improvements, it created considerable hostility among medical staff, as the matron demanded more nurses and greater independence. In 1874, the sisterhood's refusal to compromise led to some governors resigning. This harmed the hospital's ability to attract medical students (a key source of income). Despite attracting the famous surgeon, Joseph Lister, to the staff in 1877 , the resentment of doctors and managers persisted, culminating in the curtailment of the contract with St John's House in 1884. In contrast to the old regime, the new matron, Miss Monk (known as Sister Kitty), held that nurses should be loyal and helpful handmaids to the doctors and saw nursing as a vocation, not a profession.

The hospital moved to south London in 1913, encouraged both by the family of WH Smith (a major benefactor of the hospital which wanted the land here for their company) and one of its main funders, the King's Fund, which sought the migration of some central London hospitals to the suburbs. This illustrates how the Crown (which played an active role in the King's Fund) was still influencing health care in London.

their local agents - the Sheriffs and Sergeants. Although at times the Crown was in conflict with the Church, there was an underlying mutual dependence based on common interests. After all, monarchs were as susceptible to the threats of purgatory as others. And everyone lived in fear of pestilence and disease.

\section{RISE OF THE CITY}

Throughout the 12th and 13th centuries, the power of the third major player, the City, was developing. As manufacturing and trade grew, guilds to protect and

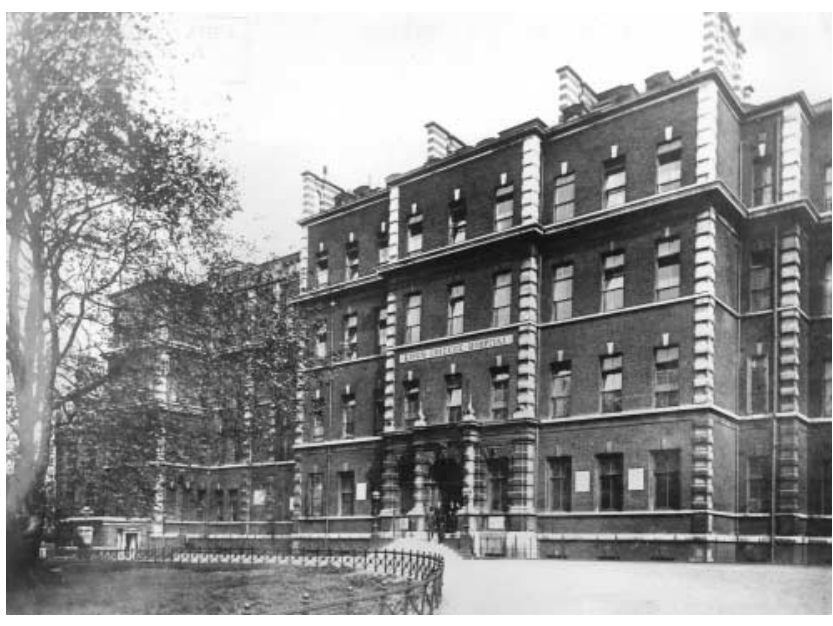

Figure 4 King's College Hospital, built in 1860, replaced the disused workhouse in which the hospital had been established in 1840. When the hospital moved to south London in 1913, the building was demolished

promote tradesmen's interests were established. These were voluntary organizations offering mutual support. By 1200 there were already 19 such guilds, and this grew to over 100 by 1400 (including the Barbers' Company). Alongside these, self-governance of the City was achieved with the right to appoint their own Sheriff (the Crown's representative) and to establish a commune with a mayor as leader. The mayor was both the voice of the City and the King's agent. The City's powers were confirmed in Magna Carta in 1215.

\section{THE REFORMATION}

Until 1500, the Church, Crown and City coexisted in, at times, an uneasy partnership. The Church continued to be the provider of hospitals for the sick and destitute. The only other health care was provided by a collection of self-taught healers, including bone-setters, corn-cutters, herbalists, midwives, barbers and tooth-pullers. Although the power of the church was increasingly viewed as exploitative, it wasn't until other circumstances (Henry VIII's desire for a divorce) arose in the 1530s that the Crown moved against the Church. The Reformation exploited widespread anticlerical feelings, some of which arose from the Church's corrupt governance of hospitals. Alms (donations) intended for the poor and needy were seen to be supporting clerics and bishops.

Starting in 1534, the Crown systematically swept away religious establishments, including the ecclesiastical palaces that lined the Strand. These were handed over to noblemen supportive of the monarch. Also destroyed were the estimated 600 hospitals in England. Often the chapel was retained and became a parish church. In other instances no 
Box 5 St Peter's Hospital for Stone

Established in 1860 in Marylebone as the Hospital for the Treatment of Stone and Urinary Diseases, this was the first hospital specializing in this field. It soon acquired a saint's name, St Peter's Hospital for Stone, consistent with the fashion of the time. Demand from patients meant more space was needed. In 1873 the governors got lucky-an unknown benefactor walked in and presented a sealed packet on the understanding it wasn't opened until he had left. It turned out to contain $£ 10000$. Such an act of generosity made the editor of the BMJ apoplectic. He viewed specialist hospitals as unnecessary 'mischievous excrescences on our system of hospital charity' and criticized the benefactor for 'perpetuating an evil.'

The result was the purpose-built premises in Henrietta Street (Figure 5), including four shops to generate rental income. In the event, demand was such that the space occupied by the shops was needed by the hospital. The date of its construction, 1882, appears above the central second floor window, and the initials of its original occupant below. Crossed keys, the symbol of St Peter, are carved over the main entrance. In 1992, together with the three other urology hospitals, it moved to the Middlesex Hospital. Since the hospital's departure the building has been converted to seven spacious apartments and shops have reoccupied the ground floor.

trace remained. However, thanks to the intervention of the City, who found the sick and infirm literally on their doorsteps, five hospitals were refounded as secular, royal hospitals, most notably St Bartholomew's, St Thomas's and St Mary of Bethlehem. In an example of cooperation between Crown and City, the governance of the royal hospitals became the responsibility of the City. The dependence of the Crown on the City for finance was balanced by the City's need for endorsement of their right to self-govern. This ensured tensions never extended to outright conflict. Their relationship has been likened to a bickering marriage in which each needed the other.

\section{URBAN GROWTH AND URBAN POVERTY}

During the 17th century, immigration led to a four-fold increase in the population of London, most of which took place outside the City. By 1660 the City housed only a quarter of the population. Building spread along the river from the City, through the village of Charing and on to Westminster. It also spread north from the Strand, with the development of Covent Garden piazza and Seven Dials. These newly fashionable areas escaped the Great Fire of 1666 which consumed much of the City.

During the following 150 years, as London continued to expand, Covent Garden passed from being fashionable to being densely populated and deprived. Piecemeal, uncontrolled development led to the creation of numerous

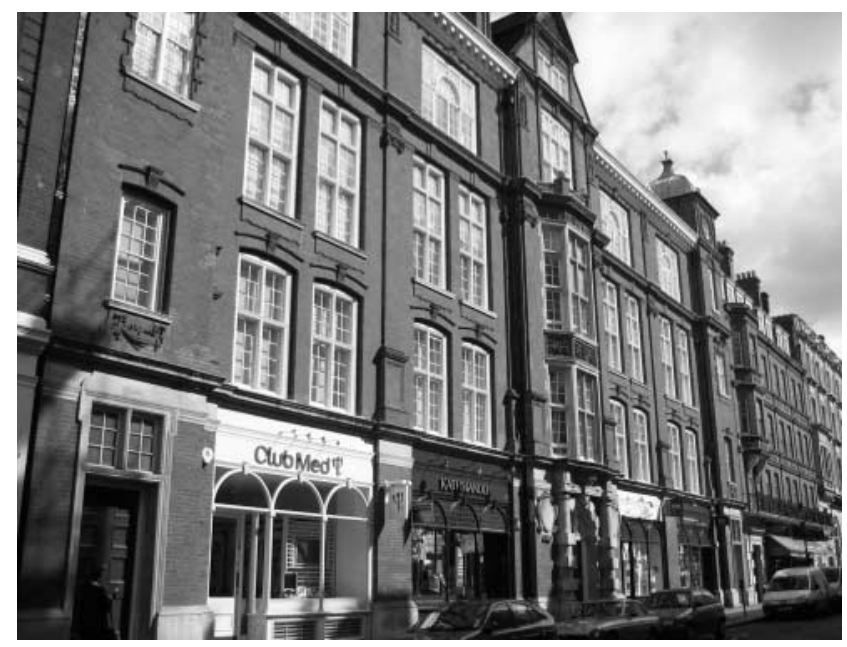

Figure 5 St Peter's Hospital for Stone (1882), with oriel windows above the central entrance and ground floor shops as an extra source of income. The hospital left in 1992 and the building was converted to apartments

courtyards. Drury Lane alone spawned 27 of these unsanitary refuges for the poor along the 500 metres between Long Acre and The Strand. Particular areas ('rookeries') developed, in which housing and living conditions were appalling. The most notorious were St Giles, Seven Dials, The Bermudas (north of the Strand) and Clare Market (near the Aldwych). Such areas posed a threat to the affluent - doctors summoned at night to the British Lying-In Hospital near Seven Dials had sedan chairs provided by the hospital to ensure their safety (Box 3).

Then, starting in the 1820 s, slum clearance programmes began. New roads were driven through the worst areas: William IV and Adelaide Streets cleared The Bermudas (1820s); New Oxford Street cut through St Giles (1847) and Short's Garden through Seven Dials (1850); and Kingsway and Aldwych cleared Clare Market (1905). Endell Street (1840s) and Charing Cross Road (1864) were built to improve travel between Holborn and the Strand. And in the 1860s, Victoria Embankment, containing the new main sewer, contributed to cleaning and redefining the riverbank. There have been few fundamental alterations since then.

\section{OTHER THEMES}

This walk also illustrates three other characteristics of health care. One is its competitive nature, in particular between teaching hospitals. Like any other industry, providers of care compete both for income and for status. Three major hospitals and their associated medical schools-King's College (Box 4), Charing Cross and Westminstercompeted in the 19th century. 
Another aspect is the international nature of health care. Many developments in London have been the result of importing ideas and innovations from abroad. Examples in Covent Garden include the first lying-in hospital in England, a direct consequence of the involvement of doctors in childbirth as a result of the importation of obstetric forceps from France; King's College Hospital, where not only nursing but hospitals themselves were reformed by religious sisterhoods based on a German model; St Peter's Hospital for Stone (Box 5), which was the first hospital in England to adopt new surgical methods from the Continent which helped establish the specialty of urology; and the Institute of Chinese Medicine, which has led the introduction of acupuncture and other therapies from China.

The final aspect of health care is the way some health care buildings live on after being abandoned by health care. In Covent Garden there are old hospital buildings being used as apartments, a hotel, a club and gallery, part of a university and a police station. And a coroner's court and mortuary now houses a nursery school. 